\title{
Properties of 5'-Nucleotidase from Carp Skeletal Muscle
}

\author{
Kazuko TomioKA ${ }^{* 1}$ and Kinji ENDO*2 \\ (Accepted March 5, 1984)
}

\begin{abstract}
The purified $5^{\prime}$-nucleotidase from carp muscle showed the optimum activity at about $\mathrm{pH} 7.5$. At above this $\mathrm{pH}, \mathrm{Mg}^{2+}$ affected the $5^{\prime}$-nucleotidase activity in a complex manner, showing a second optimum at $\mathrm{pH} 9$ in the presence of some buffer ions. ADP and ATP were effective inh ibitors of the enzyme in a manner of competitive inhibition. ADP was a far more powerful inhibitor than ATP. The enzyme activity was also inhibited by the addition of EDTA and the inhibition was dependent on the time of incubation with chelating agent. The inhibition of the enzyme by EDTA apparently followed a second order equation, $\log V_{t} / V_{0}=-k[E D T A] t$. The apoenzyme which was prepared by treatment with EDTA restored the original activity effectively by the addition of $\mathrm{Zn}^{2+}$, and was more unstable on heating than the intact enzyme.
\end{abstract}

In the previous paper, ${ }^{1)}$ the purification of $5^{\prime}$ nucleotidase (5'-nucleotide phosphohydrolase EC. 3.1.3.5) from skeletal muscle of carp has been described. It has also been shown that the purified $5^{\prime}$-nucleotidase was the key enzyme on the post-mortem degradation of inosine monophosphate (IMP) in carp muscle, and appeared to be membrane bound.

In order to control the post-mortem degradation of IMP in fish muscle during the storage, it would be useful to throw light on the enzymatic properties of 5 -nucleotidase. In the present work, some properties, mainly on the inhibitory effects of various compounds on carp muscle 5 -nucleotidase, are studied and discussed in comparison with $5^{\prime}$-nucleotidase from the other sources.

\section{Materials and Methods}

\section{Reagents}

Sephadex G-25 was purchased from Pharmacia Fine Chemicals, adenosine deaminase from Sigma Chemical Co. All other chemicals were reagent grade.

\section{$5^{\prime}$-Nucleotidase}

The enzyme used in this experiment was prepared from the skeletal muscle of carp Cyprinus carpio as shown in the previous paper, ${ }^{1)}$ and it was nearly homogenious on disc gel electrophoresis.

\section{Assay of $5^{\prime}$-Nucleotidase}

Two methods of assay were used for 5 -nucleotidase activity.

Assay $1 \quad 5^{\prime}$-Nucleotidase was assayed by the determination of the liberated orthophosphate as described previously. ${ }^{1)}$

Assay $2 \quad 5^{\prime}$-Nucleotidase was assayed using adenosine monophosphate (AMP) as substrate by converting the liberated adenosine to inosine with adenosine deaminase. The reaction mixture contained $300 \mu \mathrm{mol}$ of Tris- $\mathrm{HCl}$ buffer, $\mathrm{pH} \mathrm{7.4,0.5 \mu -}$ mol of AMP, $6 \mu \mathrm{g}$ of adenosine deaminase, and 5 'nucleotidase in a final volume of $3.0 \mathrm{ml}$. The reaction, which was started by adding 5 '-nucleotidase, was run at $20^{\circ} \mathrm{C}$. The change in absorbance at $260 \mathrm{~nm}$ was followed spectrophotometrically with a Hitachi spectrophotometer model 220-S.

\section{Results and Discussion}

\section{Effect of $p H$ on $5^{\prime}$-Nucleotidase}

The activity of the carp $5^{\prime}$-nucleotidase as a function of $\mathrm{pH}$ is shown in Fig. 1. The enzyme showed the optimum activity at a pH of about 7.5 in veronal-acetate- $\mathrm{HCl}$ buffer, and the activation of the enzyme with $\mathrm{Mg}^{2+}$ was observed at $\mathrm{pH}$ region greater than 8.0 . In the $\mathrm{pH}$ region of 7.8 to 9.8 , borate- $\mathrm{NaOH}$ buffer gave a lower activity than veronal-acetate- $\mathrm{HCl}$ buffer, but a similar activating effect of $\mathrm{Mg}^{2+}$ was observed in borate$\mathrm{NaOH}$ buffer as in veronal-acetate- $\mathrm{HCl}$ buffer. In glycine- $\mathrm{NaOH}$ buffer, $\mathrm{Mg}^{2+}$ markedly activated the enzyme in the $\mathrm{pH}$ region examined, giving a

* Nara University of Education, Nara 630, Japan (冨岡和子：奈良教育大学).

*2 Faculty of Home Economics, Nara Women's University, Nara 630, Japan（遠藤金次：系良女子大学家 政学部). 


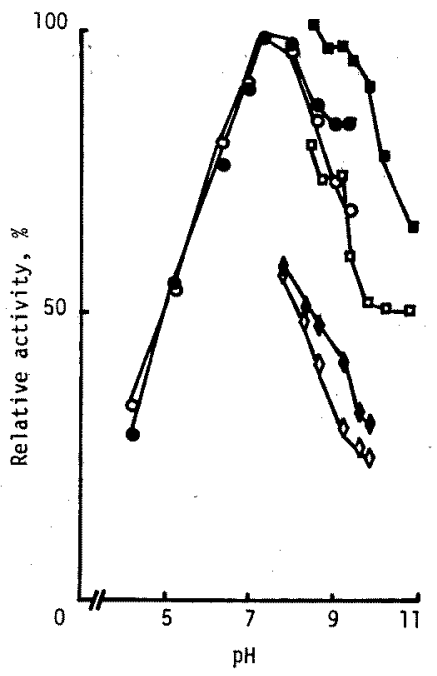

Fig. 1. Effect of $\mathrm{pH}$ on the activity of carp 5'nucleotidase in the absence or the presence of $\mathrm{Mg}^{2+}$. Assay 1 was used as described in "Materials and Methods" except that the buffer was varied. Activities were expressed relative to the activity for veronal-acetate- $\mathrm{HCl}$ buffer at a $\mathrm{pH}$ of 7.4 .

Open symbols: activity in the absence of $\mathrm{MgCl}_{2}$, solid symbols: activity in the presence of $10 \mathrm{mM}$ $\mathrm{MgCl}_{2}, 0, \bullet: \mathrm{M} / 7$ veronal-acetate-HCl buffer, $\square, \mathbf{m}: \mathrm{M} / 10$ glycine- $\mathrm{NaOH}$ buffer, $\diamond, \diamond: \mathrm{M} / 5$ borate$\mathrm{NaOH}$ buffer.

shoulder on the $\mathrm{pH}$-activity curve at a $\mathrm{pH}$ of about 9. These results indicated that $\mathrm{Mg}^{2+}$ affected the $5^{\prime}$-nucleotidase activity at above optimum $\mathrm{pH}$ in a complex manner, showing a second optimum in the presence of some buffer ions at a pH of about 9 . Values of optimum $\mathrm{pH}$ of $5^{\prime}$-nucleotidase from various animal sources were in a range of $5.5^{2,3)}$ $8.5,{ }^{47}$ and those from cod muscle, ${ }^{3)}$ rat heart, ${ }^{8,7)}$ and sheep brain ${ }^{8)}$ were similar to the present value of carp 5'-nucleotidase. The effect of $\mathrm{Mg}^{2+}$ on the pH-activity curve observed here is consistent with the results obtained with 5 -nucleotidase preparations from cod muscle, ${ }^{5)}$ carp muscle, ${ }^{\text {,) }}$ and rat heart plasma membrane. ${ }^{\circ)}$

\section{Effect of Various Substances on 5'-Nucleotidase}

Relative activity of the carp 5 -nucleotidase in the presence of some of divalent metal ions and other substances is given in Table 1. The enzyme activity was markedly suppressed by $\mathrm{Cu}^{2+}$ and $\mathrm{Zn}^{2+}$, whereas $\mathrm{Co}^{2+}$ and $\mathrm{Mn}^{2+}$ were somewhat stimulatory. Little or no effect was observed by $\mathrm{Mg}^{2+}$ and $\mathrm{Ca}^{2+}$.
Table 1. Effect of various substances on the activity of carp 5'-nucleotidase

\begin{tabular}{|c|c|c|}
\hline Additives & & $\begin{array}{c}\text { Relative activity } \\
(\%)\end{array}$ \\
\hline None & & 100 \\
\hline $\mathrm{Mg}^{2+}$ & $1 \mathrm{mM}$ & 103 \\
\hline $\mathrm{Ca}^{2+}$ & $1 \mathrm{mM}$ & 102 \\
\hline $\mathrm{Mn}^{2+}$ & $1 \mathrm{mM}$ & 120 \\
\hline $\mathrm{Co}^{2+}$ & $0.1 \mathrm{~mm}$ & 120 \\
\hline$"$ & $1 \mathrm{mM}$ & 118 \\
\hline $\mathrm{Ni}^{2+}$ & $0.1 \mathrm{~mm}$ & 96 \\
\hline$"$ & $1 \mathrm{~mm}$ & 60 \\
\hline $\mathrm{Cu}^{2+}$ & $0.01 \mathrm{~mm}$ & 60 \\
\hline " & $0.1 \mathrm{~mm}$ & 22 \\
\hline " & $1 \mathrm{mM}$ & 11 \\
\hline $\mathrm{Zn}^{2+}$ & $0.01 \mathrm{mM}$ & 96 \\
\hline " & $0.1 \mathrm{mM}$ & 56 \\
\hline " & $1 \mathrm{mM}$ & 22 \\
\hline EDTA & $1 \mathrm{~mm}$ & 33 \\
\hline $\mathrm{NaF}$ & $1 \mathrm{~mm}$ & 98 \\
\hline Cysteine & $0.01 \mathrm{~mm}$ & 102 \\
\hline " & $0.1 \mathrm{~mm}$ & 99 \\
\hline " & $1 \mathrm{~mm}$ & 42 \\
\hline Inosine & $1 \mathrm{~mm}$ & 97 \\
\hline $2^{\prime}\left(3^{\prime}\right)-\mathrm{AMP}$ & $1 \mathrm{~mm}$ & 93 \\
\hline $5^{\prime}-\mathrm{ADP}$ & $1 \mathrm{~mm}$ & 15 \\
\hline $5^{\prime}-\mathrm{ATP}$ & $1 \mathrm{~mm}$ & 58 \\
\hline
\end{tabular}

Relative activities were determined with additives range of $0.01-1 \mathrm{~mm}$ by using assay 1 .

These results indicate that the addition of some divalent metal ions was not essential for the enzymatic activity. The enzyme was markedly inhibited by ethylenediaminetetraacetic acid (EDTA) and cysteine.

Of nucleotides examined, adenosine diphosphate (ADP) and adenosine triphosphate (ATP) were also effective inhibitors of the enzyme.

\section{Kinetic Properties of $5^{\prime}$-Nucleotidase}

Kinetic properties of the carp 5'-nucleotidase were studied by employing different concentrations of IMP. A Michaelis constant of the 5'-nucleotidase for IMP was calculated to be $0.093 \mathrm{~mm}$ according to Lineweaver-Burk equation. This value is similar to that from carp muscle, ${ }^{8)}$ bovine intestinal mucosa ${ }^{10)}$ and rat heart sarcolemma, ${ }^{7)}$ two orders of magnitude smaller than that of $5^{\prime}$ nucleotidase from pigeon heart, ${ }^{11}$ one order of magnitude smaller than that from cod muscles) and bonito muscle, ${ }^{2)}$ and one order of magnitude larger than that from rat heart ${ }^{\beta)}$ and pig intestinal muscle. ${ }^{12)}$

The inhibitory effect of nucleoside di- and triphosphates on the hydrolysis of IMP by 5'-nucleoti- 


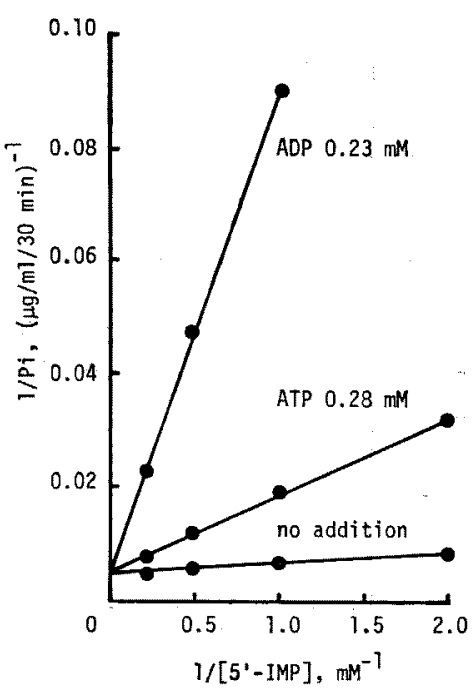

Fig. 2. Inhibitory effects of ADP and ATP on the activity of carp 5'-nucleotidase. Assay 1 was used except that IMP concentration was varied and other nucleotides were added.

dase was investigated. As shown in Fig. 2, ADP and ATP depressed the dephosphorylation of IMP by $5^{\prime}$-nucleotidase in a manner of competitive inhibition. It was also found that ADP was a far more powerful inhibitor than ATP, Ki values of these compounds being $3.1 \mu \mathrm{M}$ and $18 \mu \mathrm{M}$, respectively.

The competitive inhibition by ADP and ATP has also been reported with several 5 '-nucleotidases from other sources, ${ }^{7,10,12,132}$ and ADP was a more effective inhibitor than ATP in those enzymes. Therefore, the post-mortem degradation of IMP by $5^{\prime}$-nucleotidase in fish muscle must be depressed by ADP and ATP at some storage periods before the full rigor when the greater part of ADP and ATP in fish muscle disappears.

\section{Inhibition of 5'-Nucleotidase by EDTA}

Time course of inhibition of the carp 5'-nucleotidase in the presence of various levels of EDTA was investigated. The initial velocity of dephosphorylation of AMP by the enzyme was not affected by the addition of EDTA as shown in Fig. 3. The inhibition was dependent on the time of incubation with EDTA, and was markedly affected by the concentration of EDTA.

An inhibitory effect of EDTA has been reported on various 5 -nucleotidases from a wide variety of vertebrate sources. ${ }^{5,8,0,14)}$ Although, in most cases, the inhibition by EDTA has been considered

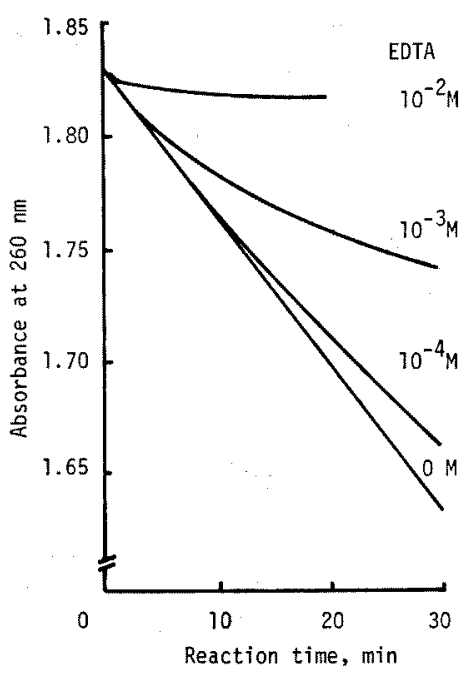

Fig. 3. Effect of EDTA on the time course of dephosphorylation of AMP by the carp 5'-nucleotidase. Changes in $E_{280}$ were continuously recorded under the experimental condition of assay 2 at $20^{\circ} \mathrm{C}$.

to be caused by chelating a bound metal ion in the enzyme, kinetics of the chelating have been remaining obscure. Then, on the assumption that the chelating would follow a second order equation, the logarithms of relative velocities of dephosphorylation of AMP, calculated from Fig. 3, were plotted against the reaction time. As shown in Fig. 4, the logarithms of relative velocities $V_{t} / V_{0}$ were linearly decreased with the reaction time, depending upon the concentration of EDTA. The rate constant of the decrease in the velocity of the enzymatic activity in the presence of EDTA, or that of the inactivation of the $5^{\prime}$-nucleotidase by chelating a bound metal ion with EDTA, calculated from the slopes of lines in Fig. 4, gave 36.0 $\min ^{-1} \cdot \mathrm{M}^{-1}$ for $10^{-2} \mathrm{M}$ EDTA, $31.3 \mathrm{~min}^{-1} \cdot \mathrm{M}^{-1}$ for $10^{-3} \mathrm{M}$ EDTA, and $33.3 \mathrm{~min}^{-1} \cdot \mathrm{M}^{-1}$ for $10^{-4} \mathrm{M}$ EDTA. These values are substantially identical, and it is reasonable, therefore, to conclude that, in the presence of excess EDTA, the inactivation of the 5 '-nucleotidase by chelating a bound metal ion with EDTA apparently follows a second order equation, $\log \mathrm{V}_{\mathrm{t}} / \mathrm{V}_{0}=-\mathrm{k}$ [EDTA]t, where [EDTA] is the concentration of EDTA added.

Effect of $5^{\prime}-A M P$ on the Inhibition of $5^{\prime}-N u c l e o t i-$ dase by EDTA

The rate constant of the inactivation of carp muscle $5^{\prime}$-nucleotidase in the presence of $10^{-3} \mathrm{M}$ EDTA, decreased with increasing concentration 


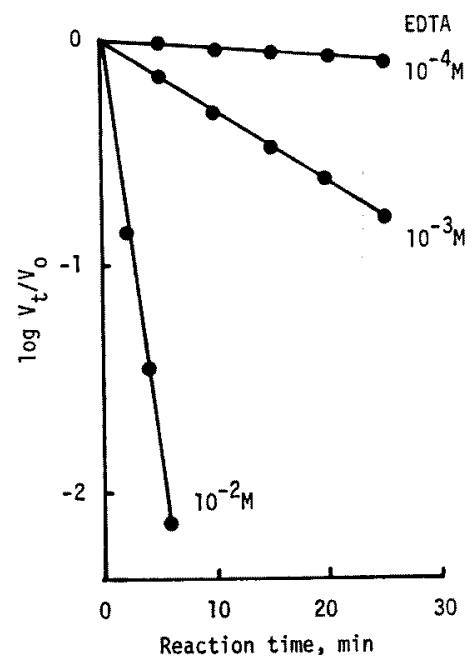

Fig. 4. Effect of EDTA concentration on the rate of inactivation of carp 5'-nucleotidase.

$\mathrm{V}_{0}$ : initial velocity of dephosphorylation of AMP by the carp $5^{\prime}$-nucleotidase.

$V_{t}$ : velocity of dephosphorylation of AMP by the carp 5'-nucleotidase in the presence of EDTA at reaction time $t$.

$V_{0}$ and $V_{t}$ were calculated from the slopes of the curves in Fig. 3.

of AMP as shown in Fig. 5 and Fig. 6. This result indicates that there is a maximum limit of AMP concentration by which the rate constant is not affected. It is also suggested that the rate constant of the chelate reaction of EDTA with a bound metal ion in the intact enzyme is larger than that with a bound metal ion in the enzyme-substrate complex. Therefore, because of the decrease in the ratio of free enzyme to enzyme-substrate complex by increasing AMP concentration, the apparent decrease may occur in the rate constant of the inactivation of enzyme by EDTA. If so, it may be reasonable to suppose that the bound metal ion in 5'-nucleotidase may play a key role in the formation of an enzyme-substrate complex, and an affinity of the metal ion for the enzyme may be increased by the formation of an enzyme-substrate complex.

\section{Reactivation of EDTA-treated 5'-Nucleotidase}

The observations mentioned above raised questions of whether EDTA removes a bound metal ion in the carp 5 '-nucleotidase or not, and whether the inhibitory effect of EDTA is reversible or not. An approach to the questions was then undertaken by studying with a apoenzyme which was prepared

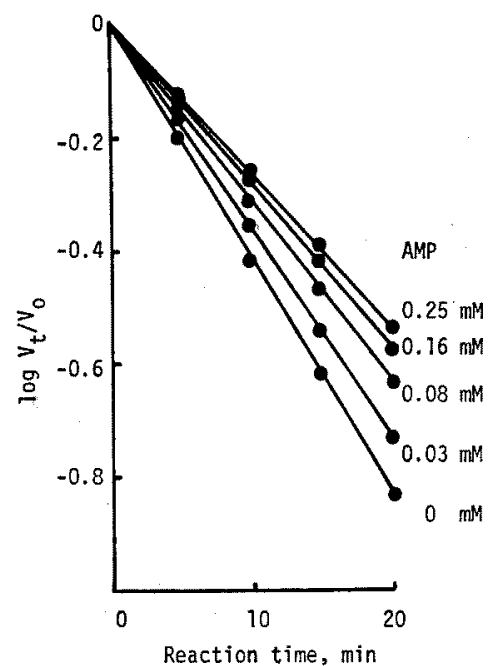

Fig. 5. Effect of AMP on the inactivation of carp 5'nucleotidase by $10^{-3} \mathrm{M}$ EDTA. In the case of 0.03-0.25 mM AMP, $V_{0}$ and $V_{t}$ were determined under the same method as shown in Fig. 4. In the case of $0 \mathrm{mM} \mathrm{AMP}$, immediately after the incubation of carp $5^{\prime}$-nucleotidase with $10^{-3} \mathrm{M}$ EDTA at $20^{\circ} \mathrm{C}$ for $t \min 0.08 \mathrm{~mm}$ AMP was added, and the initial velocity of the dephosphorylation of AMP was determined.

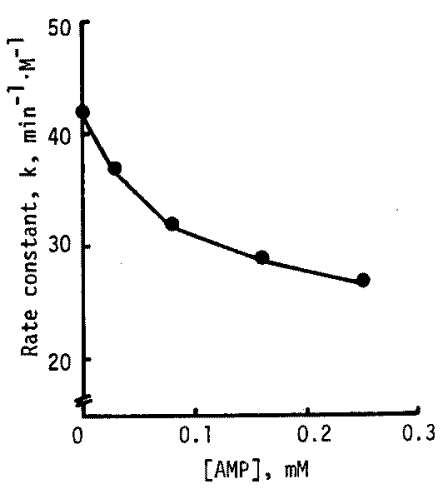

Fig. 6. Effect of AMP on the rate constant of the inactivation of carp $5^{\prime}$-nucleotidase by $10^{-3} \mathrm{M}$ EDTA. The rate constant, $\mathrm{k}$ in a equation log $\mathrm{V}_{\mathrm{t}} / \mathrm{V}_{0}=-\mathrm{k}$ [EDTA]t, was calculated from the slopes in Fig. 5.

by incubating the intact enzyme with $1 \mathrm{~mm}$ EDTA at $30^{\circ} \mathrm{C}$ for $10 \mathrm{~min}$, followed by gel filtration with Sephadex G-25. The activity of the apoenzyme was occasionally changed on the gel filtration with $0.01 \mathrm{~m}$ veronal-acetate- $\mathrm{HCl}$ buffer as an eluent. This is probably caused by traces of some metal 


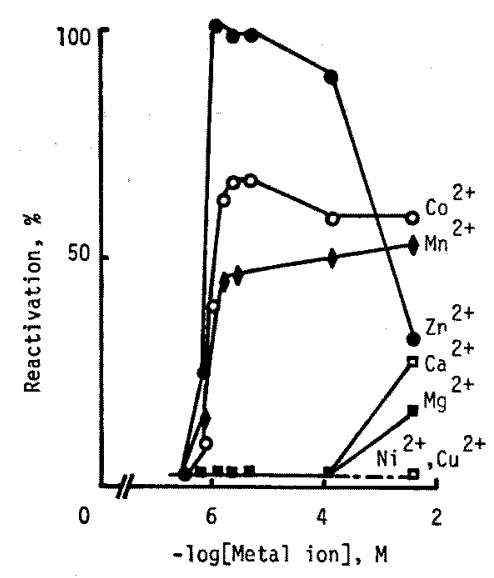

Fig. 7. Reactivation of the apoenzyme by divalent metal ions. The enzyme activity was determined by using assay 2 immediately after the addition of divalent metal ion to the apoenzyme which was prepared by incubating the 5 -nucleotidase with $1 \mathrm{~mm}$ EDTA followed by gel filtation.

ions from impurity of reagents or water used. Therefore, $0.01 \mathrm{M}$ veronal-acetate- $\mathrm{HCl}$ buffer containing $1 \mu \mathrm{M}$ EDTA was used for the gel filtration. The activity of the prepared apoenzyme did not fluctuate and the inhibitory effect of $1 \mu \mathrm{m}$ EDTA on the activity was negligibly slight. The apoenzyme having $4.4 \%$ of the original activity was scarcely reactivated by the gel filtration. However, the apoenzyme was reactivated by the addition of divalent metal ions as shown in Fig. 7.

Of divalent metal ions examined, $\mathrm{Zn}^{2+}, \mathrm{Co}^{2+}$ and $\mathrm{Mn}^{2+}$ reactivated the enzyme, and $\mathrm{Zn}^{2+}$ was the most effective, occuring a maximum reactivation at $1.15 \mu \mathrm{M}$. The reactivation by $\mathrm{Ni}^{2+}, \mathrm{Cu}^{2+}$, $\mathrm{Mg}^{2+}$ and $\mathrm{Ca}^{2+}$ was unsuccessful. The concentration of free divalent metal ions which was effective to restore the activity should be very low, because the apoenzyme solution contained $1 \mu \mathrm{M}$ EDTA.

On the basis of the fact that the activity of the apoenzyme was fully restored by the addition of $\mathrm{Zn}^{2+}$, it is reasonable to suppose that the timedependent depression of dephosphorylation of AMP with 5'-nucleotidase in the presence of EDTA is caused by the reversible removement of the bound metal ion, which is essential for the enzymatic activity, especially for the formation of the enzyme-substrate complex.

With regard to the reactivation of 5 -nucleotidases, it has been shown that the particulate 5'nucleotidase from bovine which was inactivated by acid and alkali treatments was partially reactivated with $\mathrm{Zn}^{2+}$ and other divalent metal ions. ${ }^{15)}$

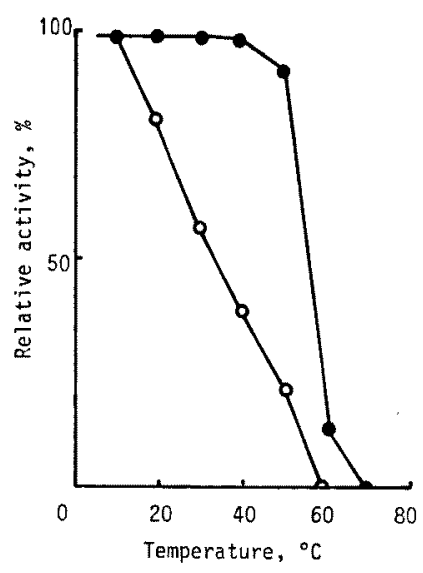

Fig. 8. Thermostability of the apoenzyme. Immediately after the heat treatment of the apoenzyme in $0.01 \mathrm{M}$ veronal-acetate- $\mathrm{HCl}$ buffer, $\mathrm{pH} 7.4$ at various temperatures for $5 \mathrm{~min}, \mathrm{Zn}^{2+}$ was added to give the final concentration of $1.15 \mu \mathrm{M}$, and then the remaining activity was determined by the method of assay 2 .

: the intact enzyme, $O$ : the apoenzyme.

On the other hand, it has been reported that the inactivation of $5^{\prime}$-nucleotidase from rat heart by EDTA was partially reversed by the removal of EDTA, and that the incubation of the EDTAtreated enzyme with various divalent metal ions failed to reactivate the enzyme. ${ }^{0)}$

\section{Thermostability of EDTA-treated 5'-Nucleotidase}

Potential enzymatic activity of the apoenzyme prepared as mentioned above was determined after the heat treatment at various temperatures. As shown in Fig. 8, the apoenzyme was unstable at temperature above $20^{\circ} \mathrm{C}$, being much more labile on heating than the intact enzyme. This instability of the apoenzyme may indicate that the metal ion which was removed by EDTA should play a role in the stabilization of three-dimensional structure of the enzyme.

As mentioned above, the carp $5^{\prime}$-nucleotidase was found to be similar to $5^{\prime}$-nucleotidases from rat heart, ${ }^{8,7)}$ pigeon heart ${ }^{11}$ and pig intestinal muscle $^{12)}$ with respect to $\mathrm{pH}$ optima in the presence or absence of $\mathrm{Mg}^{2+}$ and the inhibitory effect of ADP and ATP. This result suggests that the 5'nucleotidase having the similar properties to carp enzyme is widely distributed in muscles of higher animals. Although it has been shown that the 5'nucleotidase from heart muscle can act as a translo- 
case of adenosine which is a powerful vasodilator, ${ }^{8)}$ the physiological role of $5^{\prime}$-nucleotidase in skeletal muscle can not be well explained at present.

The inhibitory effect of EDTA on 5'-nucleotidase has been reported. ${ }^{5,8,0,14)}$ but the detailed mechanism of the inhibition has remained obscure. However, the present results indicate that EDTA may remove time-dependently a metal ion (perhaps $\mathrm{Zn}^{2+}$ ) from the carp $5^{\prime}$-nucleotidase, and that the heat-labile and metal ion-free apoenzyme is instantaneously activated by the addition of a metal ion like $\mathrm{Zn}^{2+}$ which seems to be the most effective metal ion.

The authors wish to express deep gratitude to Professor H. KaWAI, Faculty of Home Economics, Nara Women's University, for review of this manuscript and many suggestions.

\section{References}

1) K. Tomoka and K. Endo: Bull. Japan. Soc. Sci. Fish., 50, 1077-1081 (1984).

2) N. Hirota: Bull. Japan. Soc. Sci. Fish., 39, 1279-1283 (1973).

3) R. M. Burger and J. M. Lowenstein: J. Biol.
Chem., 245, 6274-6280 (1970).

4) B. L. RIemer and C. C. Widnell: Arch. Biochem. Biophys., 171, 343-347 (1975).

5) H. L. A. TARR, L. J. GaRdNeR, and P. INGRAm: J. Food Sci., 34, 637-640 (1969).

6) Y. Natro and J. M. Lowenstein: Biochem., 20, 5188-5194 (1981).

7) J. M. J. Lamers, C. E. Heyliger, V. Panagia, and N.S. Dhalla: Biochim. Biophys. Acta, 742, 568-575 (1983).

8) P. L. Ipata and G. Cercignan: FEBS Lett., 7, 129-131 (1970).

9) Y. Yamamoto, K. Endo, Y. KadowaKI, and H. KIsHIDA: J. Jpn. Soc. Nutr. Food Sci., 19, 385389 (1967).

10) M. B. Sorensen and L. G. ButLer: Arch. Biochem. Biophys., 220, 225-231 (1983).

11) W. B. Gibson and G. I. Drummond: Biochem., 11, 223-229 (1972).

12) R. M. BURger and J. M. LOWENSTEIN: Biochem., 14, 2362-2366 (1975).

13) V. Stefanovic, P. Mandel, and A. Rosenberg: J. Biol. Chem., 251, 3900-3905 (1976).

14) S. Champaneria and R. J. T. Pennington: IRCS MED.SCI., 9, 1051 (1981).

15) R. TANaka, H. Morita, and A. Teruya: Biochim. Biophys. Acta, 298, 842-849 (1973). 